\title{
Carbonic anhydrase activation enhances object recognition memory in mice through phosphorylation of the extracellular signal-regulated kinase in the cortex and the hippocampus
}

\author{
Lucas Canto de Souza ${ }^{\mathrm{a}, 1}$, Gustavo Provensi ${ }^{\mathrm{a}}$, Daniela Vullo ${ }^{\mathrm{b}}$, Fabrizio Carta ${ }^{\mathrm{a}}$, \\ Andrea Scozzafava ${ }^{\mathrm{b}}$, Alessia Costa ${ }^{\mathrm{a}}$, Scheila Daiane Schmidt ${ }^{\mathrm{a}}$, Maria Beatrice Passani ${ }^{\mathrm{c}}$, \\ Claudiu T. Supuran ${ }^{\text {a }}$, Patrizio Blandina ${ }^{\text {a, * }}$ \\ a Dipartimento di Neuroscienze, Psicologia, Area del Farmaco e Salute del Bambino, Università degli Studi di Firenze, Firenze, Italy \\ b Dipartimento di Chimica 'Ugo Schiff', Università degli Studi di Firenze, Sesto Fiorentino, Italy \\ ${ }^{c}$ Dipartimento di Scienze della Salute, Università degli Studi di Firenze, Firenze, Italy
}

\section{A R T I C L E I N F O}

\section{Article history:}

Received 18 November 2016

Received in revised form

24 February 2017

Accepted 7 March 2017

Available online 9 March 2017

\section{Keywords:}

Acetazolamide

D-phenylalanine

1-N-(4-sulfamoylphenyl-ethyl)-2,4,6-

Trimethylpyridinium perchlorate

\begin{abstract}
A B S T R A C T
Rats injected with by D-phenylalanine, a carbonic anhydrase (CA) activator, enhanced spatial learning, whereas rats given acetazolamide, a CA inhibitor, exhibited impairments of fear memory consolidation. However, the related mechanisms are unclear. We investigated if CAs are involved in a non-spatial recognition memory task assessed using the object recognition test (ORT). Systemic administration of acetazolamide to male CD1 mice caused amnesia in the ORT and reduced CA activity in brain homogenates, while treatment with D-phenylalanine enhanced memory and increased CA activity. We provided also the first evidence that D-phenylalanine administration rapidly activated extracellular signalregulated kinase (ERK) pathways, a critical step for memory formation, in the cortex and the hippocampus, two brain areas involved in memory processing. Effects elicited by D-phenylalanine were completely blunted by co-administration of acetazolamide, but not of 1-N-(4-sulfamoylphenyl-ethyl)2,4,6-trimethylpyridinium perchlorate (C18), a CA inhibitor that, differently from acetazolamide, does not cross the blood brain barrier. Our results strongly suggest that brain but not peripheral CAs activation potentiates memory as a result of ERK pathway enhanced activation.
\end{abstract}

๑) 2017 Elsevier Ltd. All rights reserved.

\section{Introduction}

Carbonic anhydrases (CAs, EC 4.2.1.1) are a family of metalloenzymes of ancient origin, that catalyze the reversible conversion of $\mathrm{CO}_{2}$ to bicarbonate and protons (Supuran, 2008). Sixteen isomers

\footnotetext{
Abbreviations: CA, Carbonic anhydrases; DI, discrimination index; tF, exploration period of the familiar object; $t \mathrm{~N}$, exploration period of new object; ERK, extracellular signal-regulated kinase; i.c.v., intracerebroventricular; i.p., intraperitoneal; LTM, long-term memory; MCT, multiple comparison test; C18, 1-N-(4sulfamoylphenyl-ethyl)-2,4,6-trimethylpyridinium perchlorate; ORT, object recognition paradigm; pERK, phosphorylated ERK; STM, short-term memory; T2, testing phase; T1, training phase.

* Corresponding author. Dip. NEUROFARBA - Universita' di Firenze, Viale Pieraccini 6, 50139, Firenze, Italy.

E-mail address: patrizio.blandina@unifi.it (P. Blandina).

${ }^{1}$ Present address: Faculdade de Ciências Farmacêuticas, Universidade Estadual Paulista-UNESP, 14801-902, Araraquara, SP, Brazil.
}

of CAs have been discovered in mammals, and they differ for catalytic activity, cellular/subcellular localization and tissue distribution (Supuran and Scozzafava, 2007). CAs exert a role in a number of physiological processes such as $\mathrm{pH}$ regulation, $\mathrm{CO}_{2}$ and $\mathrm{HCO}_{3}^{-}$ transport, bone resorption, gluconeogenesis, ureagenesis and lipogenesis (Supuran, 2008). Inhibitors of CAs have been proposed as effective compounds for the treatment of glaucoma, epilepsy, cancer and infections (Supuran, 2016). Few studies have investigated the role of CAs in cognition, although a significant decline of CAs in the brain occurs during aging (Meier-Ruge et al., 1980), and this decline is even more dramatic in brains of Alzheimer's disease patients (Meier-Ruge et al., 1984). Sparse evidence suggests that CAs influence the formation of some types of memory, specifically spatial and fear memory (Sun and Alkon, 2001; Yang et al., 2013). Indeed, rats given i.c.v. phenylalanine, a CA activator (Temperini et al., 2006), ameliorated the performance to find the hidden platform in the Morris water maze. This effect is abolished by 
treatment with acetazolamide, a CA inhibitor (Sun and Alkon, 2001). In keeping with these findings, mice genetically deficient of the CA IX isoform, when exposed to the Morris water maze test, have difficulties in learning to find the hidden platform, as well as in remembering the site of the underwater platform compared to wild type littermates (Pan et al., 2012). More recently, it was reported that rats receiving acetazolamide displayed impairment of fear memory consolidation, as demonstrated by diminished avoidance rates in the shuttle avoidance test, and step-through latencies in the passive avoidance test compared to controls (Yang et al., 2013). The mechanisms underlying CAs effects on memory remain mostly unknown. As CAs activation raises $\mathrm{HCO}_{3}^{-}$ concentrations in the hippocampus (Staley et al., 1995; Sun and Alkon, 2001), thus triggering a switch of GABAergic synaptic outputs from inhibitory to excitatory (Kaila et al., 1997), it has been suggested that under these conditions GABA may activate a subset of pyramidal neurons, thus enhancing associative memories (Sun and Alkon, 2002). More recently it has been reported that acetazolamide inhibited fear conditioning-induced extracellular signalregulated kinase (ERK) phosphorylation in the amygdala (Yang et al., 2013), that is consistent with acetazolamide-induced impairments in the consolidation of fear memory (Yang et al., 2013). Indeed, several studies have identified ERK's pivotal role in the consolidation of fear memory (Atkins et al., 1998; Giovannini et al., 2003). Nevertheless, the effects of CAs on other types of memory and the underlying molecular mechanisms have not been investigated. Reports that similar treatments may result in discrepant responses in different learning paradigms (Ambrogini et al., 2011; Cho et al., 1999), prompted us to learn the role of CAs in the object recognition paradigm (ORT). This test is a validated task to study a non-spatial working memory type based on the natural tendency of animals to explore novel objects, and not involving primary reinforcement such as food or electric shocks. We tested in the present study the effects of systemic administration of two CA inhibitors, acetazolamide, that crosses the blood-brain barrier, and 1-N-(4-sulfamoylphenyl-ethyl)-2,4,6-trimethylpyridinium perchlorate (C18), that does not (Menchise et al., 2005), on novel object recognition, and completed our observations evaluating the effects produced by the acute administration of phenylalanine, that activates CAs. We correlated the effects of these compounds on novel object recognition with those on CA activity measured in brain homogenates. ERK pathway is a central cellular signaling pathway that connects the numerous extracellular signals to the membrane receptors, cascading down to transcription factors and eventually controlling gene regulation, and has a critical role in synaptic plasticity, learning and memory (Sweatt, 2001; Thomas and Huganir, 2004). As ERK phosphorylation increased in the cortex immediately after exposure to novel objects in the training session of the ORT (Nagai et al., 2007; Orr et al., 2012), and inhibition of ERK pathway in the hippocampus (Wang et al., 2016) or the prefrontal cortex (Nagai et al., 2007) impaired the expression of long-term object recognition, we examined the effects of phenylalanine in the presence and in the absence of CA inhibitors on the phosphorylation of ERK.

\section{Experimental procedure}

\subsection{Animals}

Male CD1 mice (Harlan, Italy) were 25-35 g (b.w.) at the time of the experiment and had free access to food (4RF21; Mucedola s.r.l., Italy) and water in their home cages. They were housed in a humidity- and temperature-controlled room $\left(22-24^{\circ} \mathrm{C}\right)$ in the animal facility of Dipartimento di Neuroscienze, Psicologia, Area del Farmaco e Salute del Bambino - Universitá degli Studi di Firenze (I).
Lights were maintained on a 12-h light/12-h dark cycle (lights start at 7:00 a.m.), with all behavioral testing carried out during the light phase of the cycle. Housing, animal maintenance and all experiments were conducted in accordance with the Council Directive of the European Community (2010/63/EU) and the Italian Decreto Legislativo 26 (13/03/2014), NIH guidelines on animal care and approved and supervised by a veterinarian.

\subsection{Object recognition test}

Object recognition paradigm measures a form of memory based on short and unrepeated experiments without any reinforcement, such as food or electric shocks (Ennaceur and Delacour, 1988). Object recognition is a one-trial task, and does not involve the learning of any rule, being entirely based on the spontaneous exploratory behavior of rodents toward objects. The detailed procedure has been published previously (Provensi et al., 2016). In brief, mice were placed in a white polyvinylchloride box (70 $\times 60 \mathrm{~cm}$ and $30 \mathrm{~cm}$ high) with a grid floor that is easily cleaned, and illuminated by a 75-W lamp suspended $50 \mathrm{~cm}$ above the box. The objects to be discriminated were gray polyvinyl chloride shapes: cubes of $8 \mathrm{~cm}$ side, pyramids and cylinders of $8 \mathrm{~cm}$ height. The object recognition task consisted of a training phase (T1) and a testing phase (T2). Before T1, all mice were handled 1-2 min daily for 5 days. Twenty-four $h$ prior to T1, they were habituated for 10 min to the experimental apparatus in the absence of any object. Each mouse was subjected to the procedure separately and care was taken to remove any olfactory/taste cues by cleaning carefully the arena and test objects between trials. On the day of the experiment, the mouse was placed for 5 min into the test arena facing the same direction and in the same position in the presence of two identical plastic objects such as cubes, cylinders or pyramids (T1). The behavior of mice was videotaped, and the time spent actively exploring the objects was measured by two experienced observers unaware of the pharmacological treatment. Exploration was defined as sniffing or touching the objects with the nose and/or forepaws. Sitting on or turning around the objects was not considered exploratory behavior. T2 was performed 2 or $24 \mathrm{~h}$ after $\mathrm{T} 1$, during which, each mouse was again placed in the test arena for $5 \mathrm{~min}$ in the presence of one of the familiar objects and a novel object. The position of the objects (left/right) was randomized to prevent bias from order or place preference. Mice were placed in their home cage between trials. The behavior of mice during $\mathrm{T} 2$ was videotaped, and the exploration periods of the familiar (tF) and the new object $(\mathrm{tN})$ were measured by an experienced observer unaware of the pharmacological treatment. A discrimination index (DI) was calculated according to the formula $(\mathrm{tN}-\mathrm{tF}) /(\mathrm{tN}+\mathrm{tF})$. Care was taken to avoid place preference and olfactory stimuli by randomly changing the role (familiar or new object), and the position of the two objects during T2, and cleaning them carefully. Object recognition was carried out in an insulated room to avoid any noise that could impair the performance of the mouse. To examine the effects of CA inhibitors or activators on the object recognition memory, two separate tests examining short-term (2h; STM) and long-term (24-h; LTM) memory for objects were given in the present study. In STM experiments T2 was performed $2 \mathrm{~h}$ after T1, whereas in LTM experiments the inter-trial interval was $24 \mathrm{~h}$. Animals were arbitrarily allocated to different experimental groups and behavioral tests with controls and mice treated with the different compounds were run in the same session.

\subsection{General motor activity}

The general motor activity was determined by measuring the time in seconds in which mice were moving in the arena during $\mathrm{T} 2$, 
excluding the time spent exploring the objects and it was expressed in $s$.

\subsection{Ex vivo measurement of CA activity}

Twenty-four CD1 male mice were randomly divided in three groups and treated with saline (i.p.), acetazolamide (30 $\mathrm{mg} / \mathrm{kg}$, i.p.) or D-phenylalanine (300 mg/kg, i.p.). Sixty minutes after drug injections, they were euthanized, the brain dissected on ice and immediately homogenized in $1 \mathrm{~mL}$ of ice-cold $20 \mathrm{mM}$ Hepes buffer ( $\mathrm{pH} 7.5)$. After centrifugation at $20000 \mathrm{~g}$ for $30 \mathrm{~min}$, an Applied Photophysics stopped-flow instrument was used for assaying the CA-catalyzed $\mathrm{CO}_{2}$ hydration activity from the samples as previously described (Cincinelli et al., 2011). Briefly, phenol red (at a concentration of $0.2 \mathrm{mM}$ ) was used as an indicator working at the absorbance maximum of $557 \mathrm{~nm}$, with $20 \mathrm{mM}$ Hepes buffer (pH 7.5) and $20 \mathrm{mM} \mathrm{NaClO}_{4}$ for maintaining constant ionic strength, following the initial rates of the $\mathrm{CA}$-catalyzed $\mathrm{CO}_{2}$ hydration reaction for a period of $10-100 \mathrm{~s}$, at $20^{\circ} \mathrm{C}$. The $\mathrm{CO}_{2}$ concentrations ranged from 1.7 to $17 \mathrm{mM}$ for the determination of the kinetic parameters and inhibition constants. The CA activity of the brain sample from mice treated with saline was taken as $100 \%$.

\subsection{Western Blot analysis}

Forty-eight CD1 male mice were randomly divided in 6 groups. They received co-administrations of saline or D-phenylalanine (300 mg/kg, i.p.), acetazolamide (30 mg/kg, i.p.) or C18 (30 mg/kg, i.p.) in different combinations. Sixty min later, animals were euthanized, the brain dissected on ice and frontal cortices and hippocampi immediately isolated. Western blotting was carried out as described earlier (Fabbri et al., 2016). Briefly, the cortices and the pooled hippocampi (left and right) were individually homogenized in $200 \mu \mathrm{L}$ ice-cold lysis buffer containing protease and phosphatase inhibitors ( $50 \mathrm{mM}$ TrisHCl ( $\mathrm{pH} 7.5$ ), $50 \mathrm{mM} \mathrm{NaCl}, 10 \mathrm{mM}$ EGTA, 5 mM EDTA, 2 mM NaPP, 4 mM PNFF, 1 mM Na $\mathrm{VO}_{4}, 1.1 \mathrm{mM}$ PMSF, $20 \mu \mathrm{g} / \mu \mathrm{L}$ Leupeptin, $50 \mu \mathrm{g} / \mu \mathrm{L}$ Aprotinin, $0.1 \% \mathrm{SDS}$ ) and centrifuged at $12,000 \mathrm{rpm}$ at $4{ }^{\circ} \mathrm{C}$ for $15 \mathrm{~min}$. The supernatant was collected and total protein levels were quantified using the Pierce BCA Protein Assay (Thermo Scientific, USA). Homogenates were diluted in a mix of lysis buffer and loading buffer $2 \times(50 \mathrm{mM}$ Tris $\mathrm{pH}=6.8,100 \mathrm{mM}$ DTT, $10 \%$ Glycerol, $1 \%$ Bromophenol Blue, and 2\% SDS) and boiled for $10 \mathrm{~min}$ at $95{ }^{\circ} \mathrm{C}$. Aliquots containing $30 \mu \mathrm{g}$ total proteins were resolved by electrophoresis on a $10 \%$ SDS-polyacrylamide gel (SDSPAGE) and transferred onto polyvinylidene difluoride (PVDF) membranes (Immobilon Transfer Membranes, Millipore, USA). Blots were blocked in Tris-buffered saline, $\mathrm{pH} 7.6$ containing $0.1 \%$ of Tween 20 (TBS-T) and 5\% non-fat dry milk (Bio-Rad Laboratories, USA) for $2 \mathrm{~h}$ at room temperature and then incubated overnight at $4{ }^{\circ} \mathrm{C}$ with monoclonal antibodies against Phospho-p44/42 MAPK (ERK1/2) (Thr202/Tyr204) or p44/42 MAPK (ERK1/2) (both from Cell Signaling Technology, USA) diluted 1:2000 in TBS-T containing $5 \%$ bovine serum albumin or $5 \%$ non-fat dry milk, respectively. Immunodetection was performed with secondary antibodies (antirabbit IgG conjugated to horseradish peroxidase, Cell Signaling technology, USA) diluted 1:10,000 in TBS-T containing $1 \%$ of non-fat dry milk. Membranes were washed in TBS-T and then reactive bands were detected using enhanced chemiluminescence (Luminata Crescendo, Millipore, USA). Quantitative densitometric analysis was performed using the QuantityOne analysis software (BioRad). For each sample the ratio of phospho-Erk1/Erk1 and phospho-Erk2/Erk2 densities were calculated and all individual rates were expressed as a percentage of control group.

\subsection{Statistical analysis}

Statistical analysis was performed using GraphPad Software. The data of the object recognition test are expressed as a percentage of time spent exploring each object during T2. Each value of the Western blot analysis was calculated as the ratio of pERK/ERK densities and all the individual ratios were expressed as a percentage of controls. Statistical significance was determined using one-way ANOVA or two-way ANOVA followed by Bonferroni's multiple comparison test (MCT), Dunnett or Tukey's MCT post hoc test depending upon the various experiments. The level of significance was set at $\mathrm{P}<0.05$.

\subsection{Drug administration regimen}

Each drug was freshly prepared and dissolved into the appropriate vehicle to permit the injection of a constant volume of $1 \mathrm{~mL} /$ $100 \mathrm{~g}$ body weight to each mouse. Acetazolamide was dissolved in physiological saline $(0.9 \%$ wt./vol. $\mathrm{NaCl})$ with few drops of $\mathrm{NaOH} 1 \mathrm{~N}$ solution, C18 [1-N-(4-sulfamoylphenyl-ethyl)-2,4,6trimethylpyridinium perchlorate] and $\mathrm{D}$-phenylalanine in physiological saline. Doses of acetazolamide, C18 and D-phenylanine were calculated accordingly to indication found in previous reports (Sun and Alkon, 2001; Menchise et al., 2005; Temperini et al., 2006; Yang et al., 2013). No differences were observed in the behavior of mice receiving physiological saline or physiological saline containing few drops of $\mathrm{NaOH}$.

\subsection{Compounds}

Acetazolamide, and D-phenylalanine were purchased from Sigma-Aldrich, Milan, Italy whereas C18 was synthesized in house (Supuran, 2008). All other reagents and solvents were of HPLC grade or the highest grade available.

\section{Results}

\subsection{Memory for novel object recognition following administration of acetazolamide}

The effects of acetazolamide systemic administration on object recognition are depicted in Fig. 1. All mice received a 10-min habituation $24 \mathrm{~h}$ prior to a $5 \mathrm{~min}$ training session (T1). Acetazolamide was administered i.p. 60 min prior to T1 at doses of 15 or $30 \mathrm{mg} / \mathrm{kg}$. Controls received comparable injections of vehicle. T2 was given $2 \mathrm{~h}$ after the T1.

Two-way ANOVA revealed a significant interaction between treatment and the percentage of time spent exploring novel or familiar objects (Fig. 1 A; objects, $F_{1,52}=15.35 ; P<0.001$; treatment group, $F_{2,52}=0$; $n s$; interaction, $\left.F_{2,52}=8.652 ; P<0.001\right)$. Bonferroni's post-test revealed that only controls spent significantly more time exploring the novel object compared to the familiar one (Fig. 1 A, $P<0.001$ ). Consistently, one-way ANOVA performed on the DI revealed a significant difference across groups (Fig. 1B; $\mathrm{F}_{2,28}=4.715 ; \mathrm{P}<0.05$ ), and analysis with Bonferroni's MCT showed that DI calculated for controls was significantly larger than those of mice treated with acetazolamide (Fig. 1B). One-way ANOVA and Bonferroni's MCT failed to reveal any significant group effect on the object exploration time during T1 (vehicle: $32 \pm 15 \mathrm{~s}$; acetazolamide $15 \mathrm{mg} / \mathrm{kg}$ : $25 \pm 19 \mathrm{~s}$; acetazolamide $30 \mathrm{mg} / \mathrm{kg}: 17 \pm 9 \mathrm{~s}$; mean \pm S.E.M. of 9-10 mice) and T2 (vehicle: $13 \pm 7 \mathrm{~s}$; acetazolamide $15 \mathrm{mg} / \mathrm{kg}: 8 \pm 4 \mathrm{~s}$; acetazolamide $30 \mathrm{mg} / \mathrm{kg}$ : $12 \pm 6 \mathrm{~s}$; mean \pm S.E.M. of 9-10 mice). One-way ANOVA and Bonferroni's MCT failed to reveal any significant group effect on general motor activity among the various groups (vehicle: $212 \pm 11 \mathrm{~s}$; 
HABITUATION (10 $\mathrm{min}) \quad$ TRAINING $(5 \mathrm{~min}) \quad$ TEST $(5 \mathrm{~min})$

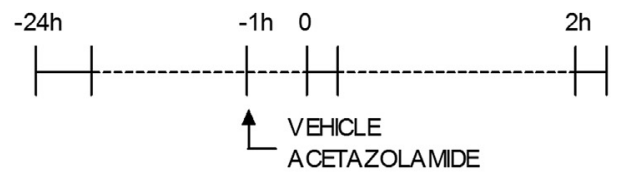

A

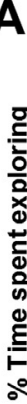

B

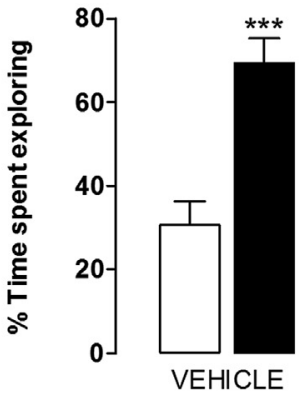

Familiar

Novel
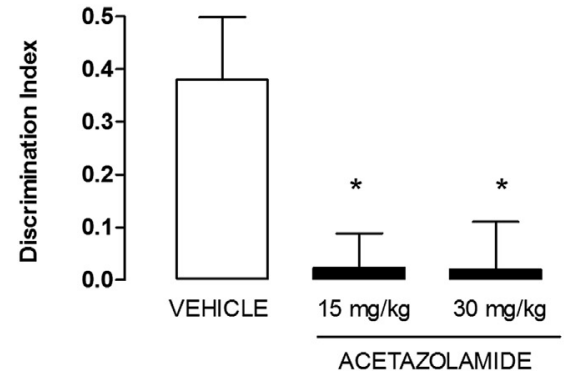

Fig. 1. Effect of acetazolamide on mice performances in the object recognition test. The schematic drawings above the graphs show the sequence of procedures and treatment administrations. (A) T2 was performed $2 \mathrm{~h}$ after training. Results are calculated as individual percentage of time spent exploring familiar (white columns) and nove (black columns) objects. Shown are means \pm S.E.M. of 9-10 animals per experimental group. ${ }^{* * *} \mathrm{P}<0.001$, vs. respective familiar object (Two-way ANOVA and Bonferroni's $\mathrm{MCT}$ ). (B) A discrimination index was calculated according to the formula $\mathrm{tN}-\mathrm{tF} / \mathrm{tN}+\mathrm{tF}$ Shown are means \pm S.E.M. of $9-10$ animals per experimental group. ${ }^{*} \mathrm{P}<0.01$, vs. vehicle (One-way ANOVA and Bonferroni's MCT)

acetazolamide $15 \mathrm{mg} / \mathrm{kg}: 213 \pm 10 \mathrm{~s}$; acetazolamide $30 \mathrm{mg} / \mathrm{kg}$ : $188 \pm 14$ s; mean \pm S.E.M. of 9-10 mice). Thus, CA inhibition elicited by acetazolamide caused amnesia of novel-object-recognition training.

\subsection{Memory for novel object recognition following administration of $\mathrm{C} 18$}

To investigate the involvement of peripheral CA in the memory for novel object recognition, we examined the effects of $\mathrm{C} 18$, a CA inhibitor that, differently from acetazolamide, does not cross the blood brain barrier. C18, freshly prepared and dissolved in physiological saline, was administered i.p. $60 \mathrm{~min}$ prior to $\mathrm{T} 1$ at the dose of 15 or $30 / \mathrm{mg} / \mathrm{kg}$. Controls received comparable injections of physiological saline. All mice received a 10 -min habituation $24 \mathrm{~h}$ prior to a 5-min T1. No significant group effects were detected during T1. During T2, given $2 \mathrm{~h}$ after the T1, all groups spent significantly more time exploring the new object rather than the familiar one (Fig. 2 A). Two-way ANOVA revealed no significant interaction between treatment and the percentage of time spent exploring novel or
HABITUATION (10 $\mathrm{m}$ in) TRAINING $(5 \mathrm{~m}$ in $) \quad$ TEST $(5 \mathrm{~m}$ in $)$
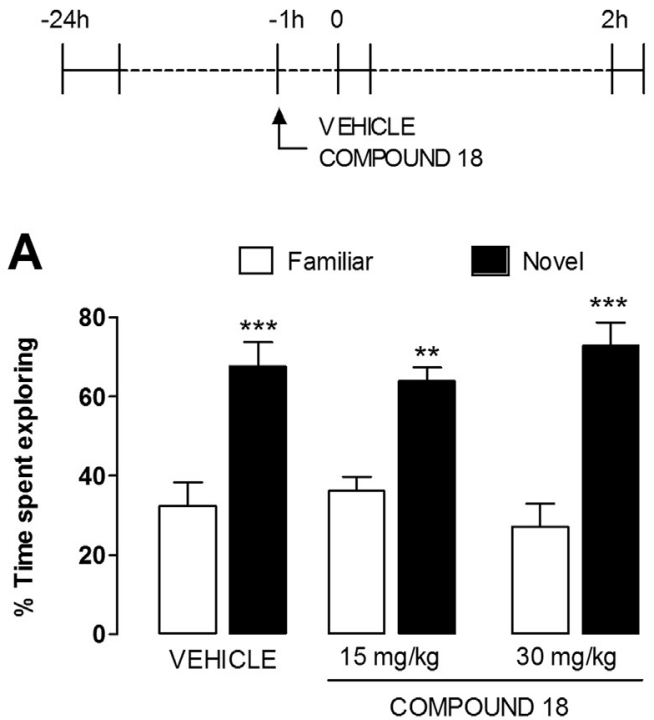

B

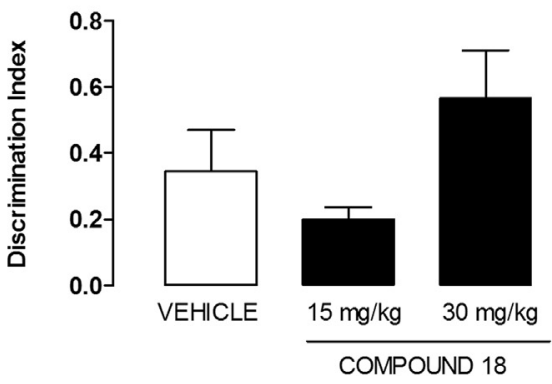

Fig. 2. Effect of $\mathrm{C} 18$ on mice performances in the object recognition test. The schematic drawings above the graphs show the sequence of procedures and treatment administrations. (A) T2 was performed $2 \mathrm{~h}$ after training. Results are calculated as individual percentage of time spent exploring familiar (white columns) and novel (black columns) objects. Shown are means \pm S.E.M. of 9-11 animals per experimental group. ${ }^{* * *} \mathrm{P}<0.001,{ }^{* *} \mathrm{P}<0.01$ vs. respective familiar object (Two-way ANOVA and Bonferroni's MCT). (B) A discrimination index was calculated according to the formula $t \mathrm{~N}-\mathrm{tF} /$ $\mathrm{tN}+\mathrm{tF}$. Shown are means \pm S.E.M. of 9-11 animals per experimental group.

familiar objects (Fig. 2A; objects, $F_{1,52}=69.71 ; P<0.001$; treatment group, $F_{2,52}=0 ; n s$; interaction, $\left.F_{2,52}=3.134 ; n s\right)$. Bonferroni's MCT revealed that each group spent significantly more time exploring the novel object compared to the familiar one (Fig. 2A). One-way ANOVA performed on the DI revealed no significant differences across groups (Fig. 2B). One-way ANOVA and Bonferroni's MCT failed to reveal any significant group effect on the object exploration time during T1 (vehicle: $27 \pm 18 \mathrm{~s} ; \mathrm{C} 1815 \mathrm{mg} / \mathrm{kg}$ : $27 \pm 18 \mathrm{~s} ; \mathrm{C} 18$ $30 \mathrm{mg} / \mathrm{kg}$ : $23 \pm 14 \mathrm{~s}$; mean \pm S.E.M. of $9-11$ mice) and T2 (vehicle: $10 \pm 7$ s; C18 $15 \mathrm{mg} / \mathrm{kg}: 10 \pm 5 \mathrm{~s} ;$ C18 $30 \mathrm{mg} / \mathrm{kg}: 6 \pm 4 \mathrm{~s}$; mean \pm S.E.M. of 9-11 mice). One-way ANOVA and Bonferroni's MCT failed to reveal any significant difference on general motor activity among the various groups (vehicle: $196 \pm 12 \mathrm{~s}$; C18 $15 \mathrm{mg} /$ kg: $240 \pm 11$ s; $C 1830 \mathrm{mg} / \mathrm{kg}: 210 \pm 14$ s; mean \pm S.E.M. of $9-11$ mice). Therefore, inhibition of CA peripheral activity elicited by $\mathrm{C} 18$ left memory for novel object recognition intact.

\subsection{D-phenylalanine administration prolongs recognition of the novel object}

We tested the effects of CA activation on the ORT by administering D-phenylalanine, an activator of several CA isoforms 
(Temperini et al., 2006). D-Phenylalanine, freshly prepared and dissolved into physiological saline, was administered i.p. $60 \mathrm{~min}$ prior to T1 at doses of $75 \mathrm{mg} / \mathrm{kg}, 150 \mathrm{mg} / \mathrm{kg}$ or $300 \mathrm{mg} / \mathrm{kg}$. Controls received comparable injections of saline. All mice received a $10-\mathrm{min}$ habituation $24 \mathrm{~h}$ prior to a 5-min T1. T2 was given $24 \mathrm{~h}$ after T1.

Two-way ANOVA revealed a significant interaction between treatment and the percentage of time spent exploring novel or familiar objects (Fig. $3 \mathrm{~A}$; objects, $F_{1,82}=3.99 ; P<0.05$; treatment group, $F_{3,82}=0 ; n s$; interaction, $F_{3,82}=2.375 ; n s$ ). Control mice displayed no statistically significant difference in the percentage of time spent exploring the familiar or the novel object (Fig. 3A), thus indicating that the present behavioral parameters are not adequate for animals to form a novel-object-recognition LTM. Mice given Dphenylalanine at 75 or $150 \mathrm{mg} / \mathrm{kg}$ behaved as the controls. Conversely, Bonferroni's MCT revealed that the mice treated with Dphenylalanine at $300 \mathrm{mg} / \mathrm{kg}$ spent significantly more time exploring the novel object compared to the respective familiar one (Fig. 3A; $\mathrm{P}<0.05$ ). One-way ANOVA performed on the DI values revealed a significant difference across groups $\left(\mathrm{F}_{3,45}=2.28\right.$; $\mathrm{P}<0.05$ ), and analysis with Bonferroni's MCT showed that DI calculated for mice given D-phenylalanine at $300 \mathrm{mg} / \mathrm{kg}$, but not at

\section{HABITUATION (10 $\mathrm{m}$ in) TRAINING $(5 \mathrm{~m}$ in) TEST $(5 \mathrm{~m}$ in)}
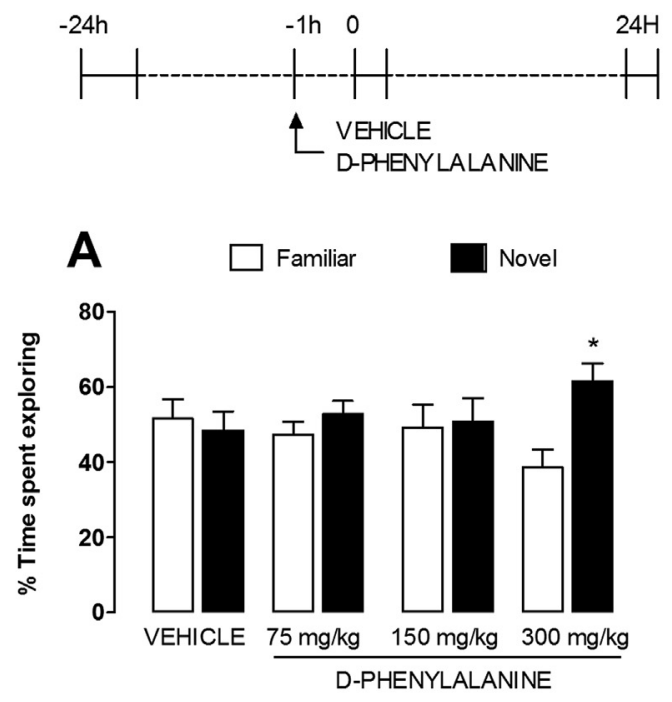

\section{B}

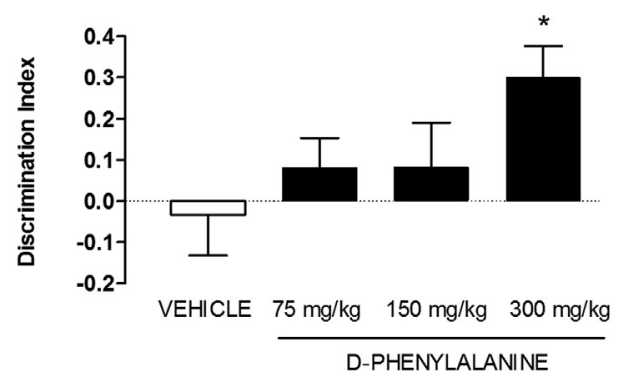

Fig. 3. Effect of D-phenylalanine on mice performances in the object recognition test. The schematic drawings above the graphs show the sequence of procedures and treatment administrations. (A) T2 was performed $24 \mathrm{~h}$ after training. Results are calculated as individual percentage of time spent exploring familiar (white columns) and novel (black columns) objects. Shown are means \pm S.E.M. of 10-12 animals per experimental group. ${ }^{*} \mathrm{P}<0.05$, vs. respective familiar object (Two-way ANOVA and Bonferroni's MCT). (B) A discrimination index was calculated according to the formula $\mathrm{tN}-\mathrm{tF} / \mathrm{tN}+\mathrm{tF}$. Shown are means \pm S.E.M. of 10-12 animals per experimental group. ${ }^{*} \mathrm{P}<0.05$, vs. vehicle (One-way ANOVA and Bonferroni's MCT).
75 or $150 \mathrm{mg} / \mathrm{kg}$, was significantly greater than DI of controls (Fig. 3B). One-way ANOVA and Bonferroni's MCT failed to reveal any significant group effect on the object exploration time during T1 (vehicle: $21 \pm 6 \mathrm{~s}$; D-phenylalanine $75 \mathrm{mg} / \mathrm{kg}$ : $19 \pm 8 \mathrm{~s}$; Dphenylalanine $150 \mathrm{mg} / \mathrm{kg}$ : $21 \pm 8 \mathrm{~s}$; D-phenylalanine $300 \mathrm{mg} / \mathrm{kg}$ : $21 \pm 14$ s; mean \pm S.E.M. of $10-12$ mice) and T2 (vehicle: $12 \pm 5$ s; Dphenylalanine $75 \mathrm{mg} / \mathrm{kg}$ : $11 \pm 7 \mathrm{~s}$; D-phenylalanine $150 \mathrm{mg} / \mathrm{kg}$ : $10 \pm 4 \mathrm{~s}$; D-phenylalanine $300 \mathrm{mg} / \mathrm{kg}$ : $14 \pm 8 \mathrm{~s}$; mean \pm S.E.M. of 10-12 mice). One-way ANOVA and Bonferroni's MCT failed to reveal any significant difference on general motor activity among the various groups (vehicle: $258 \pm 18 \mathrm{~s}$; D-phenylalanine $75 \mathrm{mg} / \mathrm{kg}$ : $257 \pm 17$ s; D-phenylalanine $150 \mathrm{mg} / \mathrm{kg}: 255 \pm 27$ s; D-phenylalanine $300 \mathrm{mg} / \mathrm{kg}: 245 \pm 18 \mathrm{~s}$; mean \pm S.E.M. of $10-12$ mice). Therefore, administration of D-phenylalanine at $300 \mathrm{mg} / \mathrm{kg}$ enhances memory for the familiar object transforming an experience that does not lead to LTM per se into one leading to LTM.

\subsection{D-Phenylalanine ability to prolong memory for the novel object} is prevented by co-administration of acetazolamide but not C18

To further assess whether better learning in D-phenylalaninetreated mice may depend on CA activation, we tested the effects of acetazolamide (30 mg/kg, i.p.) or C18 (30 mg/kg, i.p.) on the procognitive effects elicited by $300 \mathrm{mg} / \mathrm{kg}$ D-phenylalanine. Drugs were injected i.p. 60 min prior to T1. Each mouse received two injections, D-phenylalanine and acetazolamide or D-phenylalanine and $\mathrm{C} 18$. Controls received injections of physiological saline alone and associated to D-phenylalanine, acetazolamide or C18. All mice received a $10-$ min habituation $24 \mathrm{~h}$ prior to a 5 -min T1. T2 was performed $24 \mathrm{~h}$ after T1.

Two-way ANOVA revealed a significant interaction between treatment and the percentage of time spent exploring novel or familiar objects (Fig. $4 \mathrm{~A}$; objects, $F_{1,112}=3.392$; $n s$; treatment group, $F_{5,112}=0$; $n s$; interaction, $\left.F_{5,112}=5.062 ; P<0.001\right)$. Bonferroni's MCT showed that the group of mice treated with D-phenylalanine along with vehicle or C18 spent a higher percentage of time exploring the new object compared to the familiar one, whereas controls as well as mice receiving acetazolamide associated to Dphenylalanine exhibited no significant differences in the percent of time spent exploring the new or the familiar object (Fig. 4A). In keeping with these observations, DI mean values calculated for animals given vehicle or C18 and D-phenylalanine were significantly higher than those calculated for controls and for mice treated with acetazolamide and D-phenylalanine (Fig. 4B; $F_{5,61}=3.452 ; P<0.01$; one-way ANOVA and Bonferroni's MCT). One-way ANOVA and Bonferroni's MCT failed to reveal any significant group effect on the object exploration time during T1 (vehicle: $28 \pm 9 \mathrm{~s}$; vehicle + acetazolamide $30 \mathrm{mg} / \mathrm{kg}: 20 \pm 13 \mathrm{~s}$; vehicle + C18 $30 \mathrm{mg} / \mathrm{kg}: 21 \pm 13 \mathrm{~s}$; vehicle + D-phenylalanine $300 \mathrm{mg} / \mathrm{kg}$ : $296 \pm 18 \mathrm{~s}$; D-phenylalanine $300 \mathrm{mg} /$ $\mathrm{kg}+$ acetazolamide $30 \mathrm{mg} / \mathrm{kg}$ : $21 \pm 10 \mathrm{~s}$; D-phenylalanine $300 \mathrm{mg} /$ $\mathrm{kg}+$ C18 $30 \mathrm{mg} / \mathrm{kg}: 21 \pm 10 \mathrm{~s}$; mean \pm S.E.M. of 9-13 mice) and T2 (vehicle: $10 \pm 7 \mathrm{~s}$; vehicle + acetazolamide $30 \mathrm{mg} / \mathrm{kg}$ : $13 \pm 12 \mathrm{~s}$; vehicle $+\mathrm{C} 1830 \mathrm{mg} / \mathrm{kg}$ : $14 \pm 11 \mathrm{~s}$; vehicle + D-phenylalanine $300 \mathrm{mg} / \mathrm{kg}$ : $14 \pm 7$ s; D-phenylalanine $300 \mathrm{mg} / \mathrm{kg}+$ acetazolamide $30 \mathrm{mg} / \mathrm{kg}$ : $14 \pm 7 \mathrm{~s}$; D-phenylalanine $300 \mathrm{mg} / \mathrm{kg}+\mathrm{C} 1830 \mathrm{mg} / \mathrm{kg}$ : $8 \pm 5$ s; mean \pm S.E.M. of 9-13 mice). One-way ANOVA and Bonferroni's MCT failed to reveal any significant difference on general motor activity among the various groups (vehicle: $150 \pm 39 \mathrm{~s}$; vehicle + acetazolamide $30 \mathrm{mg} / \mathrm{kg}: 136 \pm 41 \mathrm{~s}$; vehicle $+\mathrm{C} 18$ $30 \mathrm{mg} / \mathrm{kg}$ : $125 \pm 24 \mathrm{~s}$; vehicle + D-phenylalanine $300 \mathrm{mg} / \mathrm{kg}$ : $236 \pm 24 \mathrm{~s}$; D-phenylalanine $300 \mathrm{mg} / \mathrm{kg}+$ acetazolamide $30 \mathrm{mg} / \mathrm{kg}$ : $191 \pm 34$ s; D-phenylalanine $300 \mathrm{mg} / \mathrm{kg}+\mathrm{C} 1830 \mathrm{mg} / \mathrm{kg}$ : $137 \pm 50 \mathrm{~s}$; mean \pm S.E.M. of $9-13$ mice). Therefore, inhibition of brain CAs through acetazolamide, but not of peripheral CA by C18, abolished 
HABITUATION (10 $\mathrm{min})$ TRAINING $(5 \mathrm{~min}) \quad$ TEST $(5 \mathrm{~min})$
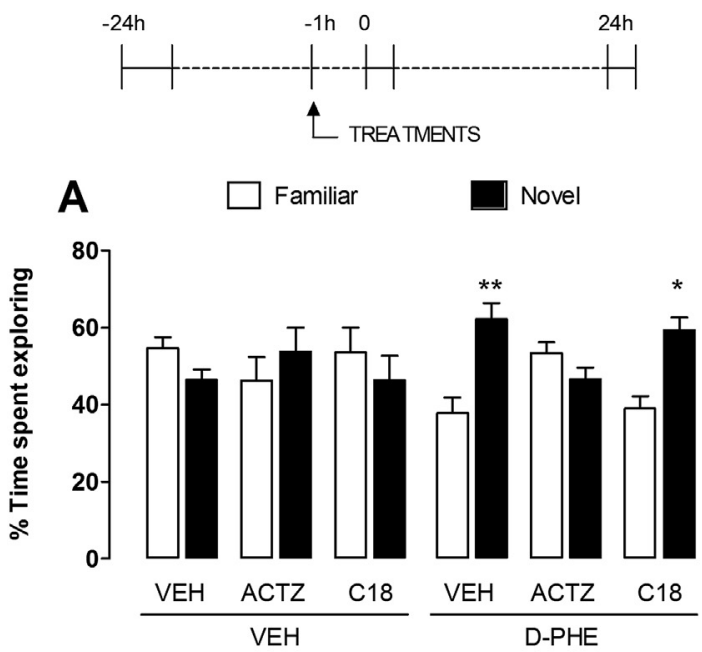

B

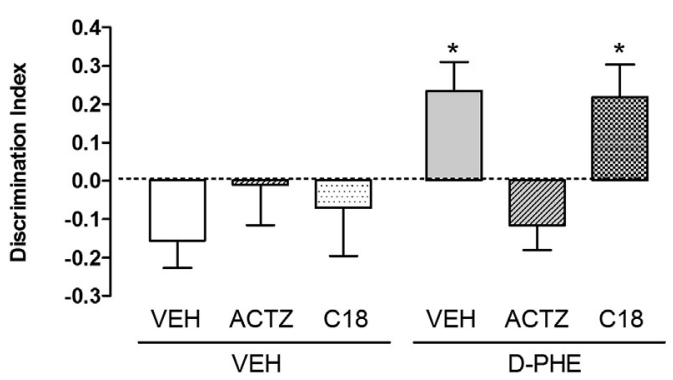

Fig. 4. Effect of co-administration of D-phenylalanine (D-PHE) and acetazolamide (ACTZ) or $\mathrm{C} 18$ on mice performances in the object recognition test. The schematic drawings above the graphs show the sequence of procedures and treatment administrations. (A) T2 was performed $24 \mathrm{~h}$ after training. Results are calculated as individual percentage of time spent exploring familiar (white columns) and novel (black columns) objects. Shown are means \pm S.E.M. of 9-13 animals per experimental group. ${ }^{* *} \mathrm{P}<0.001$, ${ }^{*} \mathrm{P}<0.05$ vs. respective familiar object (Two-way ANOVA and Bonferroni's $\mathrm{MCT}$ ). (B) A discrimination index was calculated according to the formula $\mathrm{tN}-\mathrm{tF} / \mathrm{tN}+\mathrm{tF}$. Shown are means \pm S.E.M. of $9-13$ animals per experimental group. ${ }^{*} \mathrm{P}<0.05$, vs. vehicle (VEH) (One-way ANOVA and Bonferroni's MCT).

memory enhancement for the familiar object elicited by Dphenylalanine.

\subsection{Effects of acetazolamide and D-phenylalanine systemic treatment on brain CA activity}

To examine the influences of acetazolamide and D-phenylalanine systemic treatment on brain CA activity, CD1 male mice were given acetazolamide (30 mg/kg, i.p.) or D-phenylalanine $(300 \mathrm{mg} /$ $\mathrm{kg}$, i.p.). Controls received a comparable injection of saline. Mice were euthanized $60 \mathrm{~min}$ after the injection, brains were immediately dissected on ice and homogenized individually in $1 \mathrm{~mL}$ of icecold $20 \mathrm{mM}$ Hepes buffer ( $\mathrm{pH} 7.5$ ). The catalytic activity $\left(\mathrm{k}_{\text {cat }}\right)$ of each individual preparation was measured with a stopped flow spectrophotometric method that monitors the physiological reaction catalyzed by these enzymes: $\mathrm{CO}_{2}$ hydration to bicarbonate and protons. Results are shown in Fig. 5. One way ANOVA revealed an overall difference in $\mathrm{k}_{\mathrm{cat}}$ between groups $\left(\mathrm{F}_{2,23}=66.53, \mathrm{P}<0.0001\right)$ and post-hoc analysis with Tukey's MCT showed that brain mean $\mathrm{k}_{\text {cat }}$ of acetazolamide- and D-phenylalanine-treated mice were significantly different from that of saline-treated control animals, namely it was significantly lower in acetazolamide-treated mice

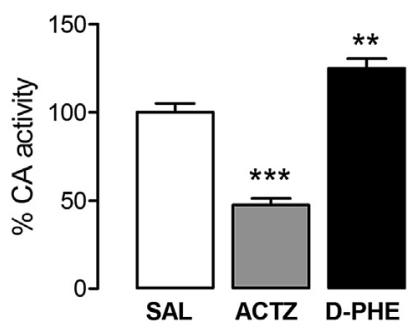

Fig. 5. CA activity (\%) in brain homogenates from mice treated with saline (SAL), acetazolamide (ACTZ, $30 \mathrm{mg} / \mathrm{kg}$, i.p.) or D-phenylalanine (D-PHE, $300 \mathrm{mg} / \mathrm{kg}$, i.p.). Animals were killed $1 \mathrm{~h}$ after drug injection and brains immediately homogenized. The CA activity of the SAL mice was taken as $100 \%$. Data are expressed as means \pm S.E.M. of 6 mice per experimental group. ${ }^{* *} \mathrm{P}<0.01,{ }^{* * *} \mathrm{P}<0.001$ vs. SAL (One-way ANOVA and Tukey's MCT).

and significantly higher in D-phenylalanine-treated animals (Fig. 5).

3.6. ERK1 and ERK2 phosphorylation in mouse cortex and hippocampus elicited by systemic administration of D-phenylalanine in the absence or the presence of acetazolamide or C18

ERK pathway in frontal-cortical and hippocampal regions is critical for various forms of long-term memory (Giovannini et al., 2003; Thomas and Huganir, 2004), including object memory (Bozon et al., 2003; Kelly et al., 2003). Here we asked whether i.p. injection of D-phenylalanine significantly increases cortical and/or hippocampal levels of phosphorylated ERK proteins (pERK) $1 \mathrm{~h}$ after injection, and tested the effects of systemic co-administration of acetazolamide or C18. Levels of pERK1 and pERK2 were determined in cortical and hippocampal homogenates of 6 groups of mice euthanized $1 \mathrm{~h}$ after i.p. injections of 1 ) saline and saline, 2) saline and acetazolamide (30 mg/kg), 3) saline and C18 (30 mg/kg), 4) D-phenylalanine $(300 \mathrm{mg} / \mathrm{kg})$ and saline, 5) D-phenylalanine (300 $\mathrm{mg} / \mathrm{kg}$ ) and acetazolamide (30 mg/kg), and 6) D-phenylalanine (300 mg/kg) and C18 (30 mg/kg). Immediately after sacrifice, the brain was dissected on ice, and the frontal cortex and hippocampi (left and right) isolated. Western blotting was carried out as described earlier (Fabbri et al., 2016). Mice given 2 injections of saline [group 1: saline and saline] served as controls. Representative immunoblots and the densitometric analysis are shown in Fig. 6. One-way ANOVA performed on pERK1/ERK1 $\left(\mathrm{F}_{5,46}=7.601\right.$; $\mathrm{P}<0.0001$; Fig. 5A $)$ and pERK2/ERK2 $\left(\mathrm{F}_{5,46}=5.697 ; \mathrm{P}<0.001\right.$; Fig. 5B) ratios in cortical homogenates revealed a significant difference across groups. Further analysis with Dunnett's test showed that pERK1/ERK1 (Fig. 6A) and pERK2/ERK2 (Fig. 6B) ratios were significantly increased in animals treated with $\mathrm{D}$-phenylalanine and saline as well as in those treated with D-phenylalanine and C18 compared to controls. Also in hippocampal homogenates one-way ANOVA performed on pERK1/ERK1 $\left(\mathrm{F}_{5,46}=5.815 ; \mathrm{P}<0.001\right.$; Fig. 5C) and pERK2/ERK2 $\left(\mathrm{F}_{5,46}=4.634 ; \mathrm{P}<0.01\right.$; Fig. 5D) ratios revealed a significant difference across groups. Further analysis with Dunnett's MCT showed that pERK1/ERK1 (Fig. 6C) and pERK2/ ERK2 (Fig. 6D) ratios were significantly increased in animals treated with D-phenylalanine and saline as well as in those treated with Dphenylalanine and C18 compared to controls. Thus, D-phenylalanine activated both cortical and hippocampal ERK1 and ERK2, and these effects were not antagonized by blockade of peripheral CAs activity through C18 administration. Conversely, blockade of brain CAs activity by means of acetazolamide abolished D-phenylalanineelicited increase of pERK1 and pERK2 (Fig. 6A, B, C and D). Infusion of either acetazolamide or C18 did not modify pERK1 or pERK2 levels compared with control group (Fig. 6A, B, C and D). 


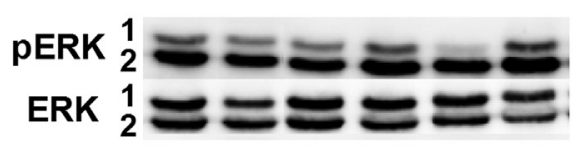

A

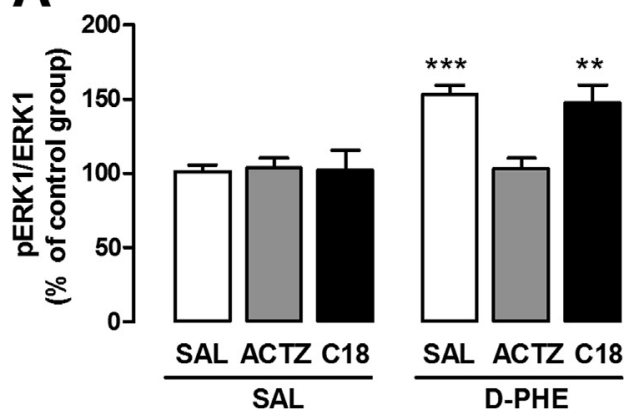

B
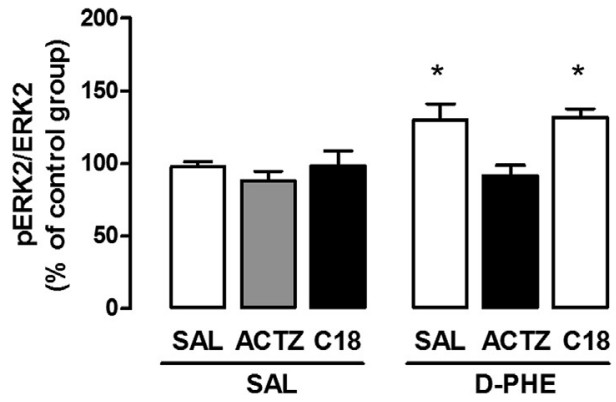

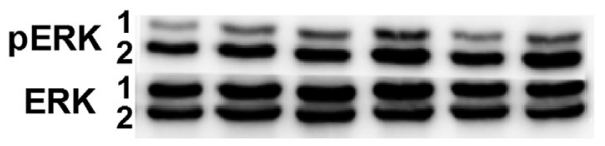

C

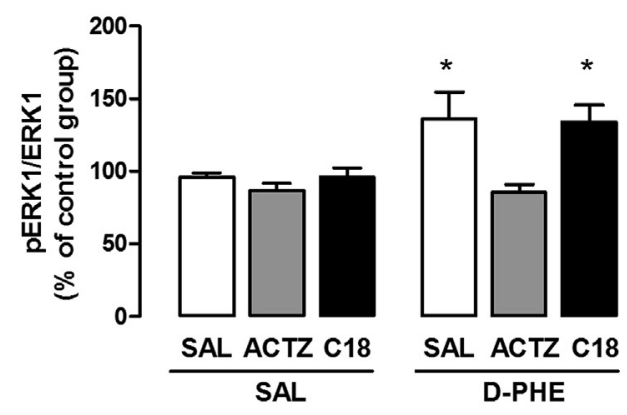

D

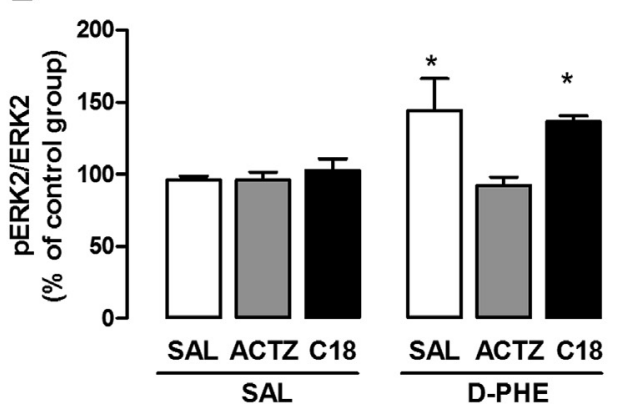

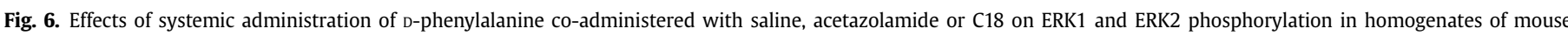

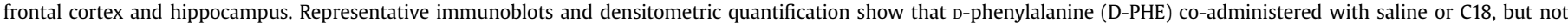

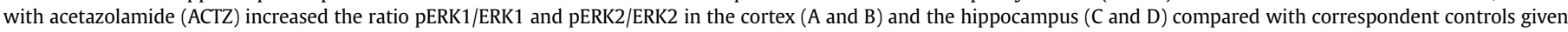

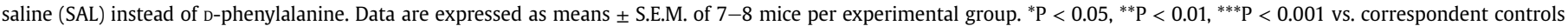
(One-way ANOVA and Dunnett's MCT).

\section{Discussion}

The present study confirms earlier suggestions of the involvement of CAs in cognitive functions (Sun and Alkon, 2002). Indeed, administration of $\mathrm{D}$-phenylalanine, a CA activator, caused the rats to exhibit superior learning of spatial memory (Sun and Alkon, 2001), the same memory type that was impaired in CA IX-deficient mice (Pan et al., 2012). In another type of memory, there is evidence that acetazolamide impaired fear memory consolidation (Yang et al., 2013). Here we investigated the role of CAs in the novel object recognition test by assessing the effects of two CA inhibitors, acetazolamide and C18, as well as a CA activator, D-phenylalanine. The novel object recognition test investigates a non-spatial working memory type that requires intact cortical and hippocampal cholinergic neurotransmission (Winters et al., 2008). Pre-training, systemic administration of acetazolamide clearly impaired shortterm memory in object recognition, as all acetazolamide-treated animals spent equal time in the exploration of the familiar or the novel object in the test session performed $2 \mathrm{~h}$ after the training session, whereas all vehicle-treated mice spent more time exploring the novel object rather than the familiar one. The different exploration times were irrelevant to locomotion, as no significant difference in the general motor activity was detected comparing control animals with those given acetazolamide. The observed lack of effects by acetazolamide on locomotion is in agreement with previous studies (Yang et al., 2013), and fits well with the report that CA IX-deficient mice only showed less locomotor activity at 2 months of age, but similar or better locomotor activity at an older age (Pan et al., 2012). Incidentally, we observed that also treatments with other substances modulating CAs activity, such as C18 or D-phenylalanine, failed to influence mice general motor activity. On the other hand, a detrimental effect on cognition by acetazolamide has been reported also in humans, as a randomized, double-blind, placebo controlled study showed that this CAs inhibitor impaired cognitive performance, executive function, short-term memory, and sustained attention during acute high-altitude exposure (Wang et al., 2013). Additional evidence supporting that CAs inhibition may impair memory in humans has come from studies on topiramate, an antiepileptic drug that also inhibits CA (Casini et al., 2003; Dodgson et al., 2000). Epileptic patients taking this drug showed deterioration in many domains of cognition that was reverted in those patients who had topiramate withdrawn or reduced (Donegan et al., 2015; Thompson et al., 2000). However, caution is necessary in the interpretation of these findings, as topiramate has multiple effects in addition to inhibition of CAs, including enhancement of GABA transmission, blockade of glutamate neurotransmission, modulation of voltagegated sodium and calcium ion channels that might underlie its negative impact on cognition. The present study reports that systemic administration of acetazolamide (30 mg/kg, i.p) caused a significant decrease of CAs activity in brain homogenates of mice euthanized 60 min after drug injection. As acetazolamide caused amnesia as well as reduced CAs activity at the same dose and in the same time range, it is conceivable that memory impairment 
occurred as a consequence of CAs inhibition. Hence, if cognitive deficits are related to reduced CAs activity, increasing CAs activity would be expected to improve cognition. The present study substantiates this prediction: treatment of mice with the same dose of D-phenylalanine, a CA activator, increased significantly CAs activity in brain homogenates 60 min after injection, and lead to improved performances in the memory task when given 60 min prior T1. Indeed, we found that D-phenylalanine administration generates a type of long-term memory that persists up to $24 \mathrm{~h}$ after training, a time point at which, using our experimental protocol, memory of a novel object fails (Ennaceur and Delacour, 1988; Provensi et al., 2016). Co-administration of acetazolamide with D-phenylalanine fully blocked the observed memory improvement, thus clearly indicating a critical role of CAs activation as underlying mechanism, and ruling out possible contributions of other D-phenylalanine effects, such as facilitation of catecholamine synthesis and/or transmission. The lack of effect in causing amnesia, directly or antagonizing D-phenylalanine-elicited memory improvements, by C18, a compound that inhibits CAs, and, differently from acetazolamide, does not cross the blood brain barrier, indicates that the targeted CAs are in the brain.

Consolidation of newly acquired information is a necessary process for the establishment of long-lasting memories (McGaugh, 2000), and requires activation of the genetic machinery and synthesis of new proteins (Abel and Lattal, 2001). ERK pathway activation, which triggers the genomic response in neurons (Davis et al., 2000; Waltereit et al., 2001), is a critical step for consolidation of different forms of long-term memories (Adams and Sweatt, 2002; Giovannini et al., 2003), including that for object recognition (Bozon et al., 2003; Nagai et al., 2007). Indeed, blocking ERK activation by inhibiting mitogen-activated protein kinase (MEK, that activates ERK) by administration of UO126 or SL327 in the cortex and/or in the hippocampus impaired consolidation of object recognition long-term memory (Bozon et al., 2003; Nagai et al., 2007; Kelly et al., 2003). Noteworthy, administration of MEK inhibitors failed to modify object recognition short-term memory (Nagai et al., 2007; Kelly et al., 2003). This is in line with reports of several drug treatments impairing long-term memory, while leaving short-term memory intact (Izquierdo and McGaugh, 2000; Benetti et al., 2015), and confirms that short-term and long-term memories are separate processes (Izquierdo et al., 1998). Another unique finding in this study is that systemic administration of Dphenylalanine significantly increased cortical and hippocampal levels of both phosphorylated ERK1 and ERK2 proteins $1 \mathrm{~h}$ after injection, and that this increase was antagonized specifically by the co-administration of acetazolamide, but not of C18. Taken together, the present findings strongly suggest that the regulation by Dphenylalanine of ERK1and ERK2 signaling in the cortex and in the hippocampus plays a role in long-term recognition memory. It has been recently reported that progesterone-as well as estradiolinduced enhancement of object recognition long-term memory depend on the activation of ERK pathway in the hippocampus (Fernandez et al., 2008; Orr et al., 2012). Therefore, we suggest that the CA activation-dependent increased expression of pERK is necessary to transform a short-term memory in a long-term memory.

In conclusion, the present study provides several novel insights into the CAs involvement in cognition. First, the present data demonstrate that selective inhibition of CAs in the brain correlates with impairments of short-term novel object recognition memory. Second, the current data demonstrate that selective activation of CAs in the brain has a beneficial effect in the novel object recognition memory by transforming a short-term learning event into a long-lasting memory. Finally, we provided the first evidence that CAs activation in the brain can rapidly activate ERK pathways in the cortex and in the hippocampus and, therefore, can likely and rapidly regulate protein synthesis, thereby ultimately lead to structural synaptic changes that facilitate memory encoding.

\section{Disclosure statement}

The authors declare no conflict of interest.

\section{Author contribution}

Lucas Canto de Souza, Gustavo Provensi, Alessia Costa and Scheila Daiane Schmidt designed the research study, performed the research (behavioral experiments and Western Blot), analyzed the data.

Daniela Vullo designed the research study, performed the research (measurement of CA activity), analyzed the data.

Fabrizio Carta designed the research study, synthetized C18, performed the research (measurement of CA activity), analyzed the data.

Andrea Scozzafava, Maria Beatrice Passani and Claudiu T. Supuran designed the research study, analyzed the data.

Patrizio Blandina designed the research study, analyzed the data, wrote the paper.

\section{Conflict of interest statement}

Lucas Canto de Souza, Gustavo Provensi, Daniela Vullo, Fabrizio Carta, Andrea Scozzafava, Alessia Costa, Scheila D Schmidt, Maria Beatrice Passani, Claudiu T. Supuran, Patrizio Blandina declare no conflict of interest.

\section{Acknowledgements}

This research was supported by University of Firenze funds (M.B.P. and P.B.), "AMBROSIAC" JPI-A Healthy Diet for a healthy life and Fondazione Ente Cassa di Risparmio Firenze (I) (M.B.P.). L. Canto-de-Souza was recipient of FAPESP research fellowship (Proc. 2012/05838-0). G. Provensi was recipient of research fellowships granted by Conselho Nacional de Desenvolvimento Científico e Tecnológico (CNPq Brazil, process 201511/2014-2) and Fondazione Umberto Veronesi.

\section{References}

Abel, T., Lattal, K.M., 2001. Molecular mechanisms of memory acquisition, consolidation and retrieval. Curr. Opin. Neurobiol. 11, 180-187.

Adams, J.P., Sweatt, J.D., 2002. Molecular psychology: roles for the ERK MAP kinase cascade in memory. Annu. Rev. Pharmacol. Toxicol. 42, 135-163.

Ambrogini, P., Ciuffoli, S., Lattanzi, D., Minelli, A., Bucherelli, C., Baldi, E., Betti, M., Cuppini, R., 2011. Maternal dietary loads of $\alpha$-tocopherol differentially influence fear conditioning and spatial learning in adult offspring. Physiol. Behav. 104, 809-815.

Atkins, C.M., Selcher, J.C., Petraitis, J.J., Trzaskos, J.M., Sweatt, J.D., 1998. The MAPK cascade is required for mammalian associative learning. Nat. Neurosci. 1, 602-609.

Benetti, F., Furini, C.R., de Carvalho Myskiw, J., Provensi, G., Passani, M.B., Baldi, E., Bucherelli, C., Munari, L., Izquierdo, I., Blandina, P., 2015. Histamine in the basolateral amygdala promotes inhibitory avoidance learning independently of hippocampus. Proc. Natl. Acad. Sci. U. S. A. 112, E2536-E2542.

Bozon, B., Kelly, A., Josselyn, S.A., Silva, A.J., Davis, S., Laroche, S., 2003. MAPK, CREB and zif268 are all required for the consolidation of recognition memory. Philos. Trans. R. Soc. Lond B Biol. Sci. 358, 805-814.

Casini, A., Antel, J., Abbate, F., Scozzafava, A., David, S., Waldeck, H., Schäfer, S., Supuran, C.T., 2003. Carbonic anhydrase inhibitors: SAR and X-ray crystallographic study for the interaction of sugar sulfamates/sulfamides with isozymes I, II and IV. Bioorg Med. Chem. Lett. 13, 841-845.

Cho, Y.H., Friedman, E., Silva, A.J., 1999. Ibotenate lesions of the hippocampus impair spatial learning but not contextual fear conditioning in mice. Behav. Brain Res, 98, 77-87.

Cincinelli, A., Martellini, T., Innocenti, A., Scozzafava, A., Supuran, C.T., 2011. Purification and inhibition studies with anions and sulfonamides of an $\alpha$-carbonic 
anhydrase from the Antarctic seal Leptonychotes weddellii. Bioorg. Med. Chem. 19, 1847-1851.

Davis, S., Vanhoutte, P., Pages, C., Caboche, J., Laroche, S., 2000. The MAPK/ERK cascade targets both Elk-1 and cAMP response element-binding protein to control long-term potentiation-dependent gene expression in the dentate gyrus in vivo. J. Neurosci. 20, 4563-4572.

Dodgson, S.J., Shank, R.P., Maryanoff, B.E., 2000. Topiramate as an inhibitor of carbonic anhydrase isoenzymes. Epilepsia 41 (Suppl. 1), S35-S39.

Donegan, S., Dixon, P., Hemming, K., Tudur-Smith, C., Marson, A., 2015. A systematic review of placebo-controlled trials of topiramate: how useful is a multipleindications review for evaluating the adverse events of an antiepileptic drug? Epilepsia 56, 1910-1920.

Ennaceur, A., Delacour, J., 1988. A new one-trial test for neurobiological studies of memory in rats. 1: behavioral data. Behav. Brain Res. 31, 47-59.

Fabbri, R., Furini, C.R., Passani, M.B., Provensi, G., Baldi, E., Bucherelli, C., Izquierdo, I., de Carvalho Myskiw, J., Blandina, P., 2016. Memory retrieval of inhibitory avoidance requires histamine $\mathrm{H} 1$ receptor activation in the hippocampus. Proc. Natl. Acad. Sci. U. S. A. 113, E2714-E2720.

Fernandez, S.M., Lewis, M.C., Pechenino, A.S., Harburger, L.L., Orr, P.T., Gresack, J.E., Schafe, G.E., Frick, K.M., 2008. Estradiol-induced enhancement of object memory consolidation involves hippocampal extracellular signal-regulated kinase activation and membrane-bound estrogen receptors. J. Neurosci. 28, 8660-8667.

Giovannini, M.G., Efoudebe, M., Passani, M.B., Baldi, E., Bucherelli, C., Giachi, F., Corradetti, R., Blandina, P., 2003. Improvement in fear memory by histamineelicited ERK2 activation in hippocampal CA3 cells. J. Neurosci. 23, 9016-9023.

Izquierdo, I., Barros, D.M., Mello e Souza, T., de Souza, M.M., Izquierdo, L.A., Medina, J.H., 1998. Mechanisms for memory types differ. Nature 393, 635-636. Izquierdo, I., McGaugh, J.L., 2000. Behavioural pharmacology and its contribution to the molecular basis of memory consolidation. Behav. Pharmacol. 11, 517-534.

Kaila, K., Lamsa, K., Smirnov, S., Taira, T., Voipio, J., 1997. Long-lasting GABAmediated depolarization evoked by high-frequency stimulation in pyramidal neurons of rat hippocampal slice is attributable to a network-driven, bicarbonate-dependent K+ transient. J. Neurosci. 17, 7662-7672.

Kelly, A., Laroche, S., Davis, S., 2003. Activation of mitogen-activated protein kinase/ extracellular signal-regulated kinase in hippocampal circuitry is required for consolidation and reconsolidation of recognition memory. J. Neurosci. 23, 5354-5360.

McGaugh, J.L., 2000. Memory-a century of consolidation. Science 287, 248-251.

Meier-Ruge, W., Iwangoff, P., Reichlmeier, K., 1984. Neurochemical enzyme changes in Alzheimer's and Pick's disease. Arch. Gerontol. Geriatr. 3, 161-165.

Meier-Ruge, W., Iwangoff, P., Reichlmeier, K., Sandoz, P., 1980. Neurochemical findings in the aging brain. Adv. Biochem. Psychopharmacol. 23, 323-338.

Menchise, V., De Simone, G., Alterio, V., Di Fiore, A., Pedone, C., Scozzafava, A., Supuran, C.T., 2005. Carbonic anhydrase inhibitors: stacking with Phe131 determines active site binding region of inhibitors as exemplified by the X-ray crystal structure of a membrane-impermeant antitumor sulfonamide complexed with isozyme II. J. Med. Chem. 48, 5721-5727.

Nagai, T., Takuma, K., Kamei, H., Ito, Y., Nakamichi, N., Ibi, D., Nakanishi, Y., Murai, M., Mizoguchi, H., Nabeshima, T., Yamada, K., 2007. Dopamine D1 receptors regulate protein synthesis-dependent long-term recognition memory via extracellular signal-regulated kinase $1 / 2$ in the prefrontal cortex. Learn Mem. 14, $117-125$.
Orr, P.T., Rubin, A.J., Fan, L., Kent, B.A., Frick, K.M., 2012. The progesterone-induced enhancement of object recognition memory consolidation involves activation of the extracellular signal-regulated kinase (ERK) and mammalian target of rapamycin (mTOR) pathways in the dorsal hippocampus. Horm. Behav. 61, 487-495.

Pan, P.W., Parkkila, A.K., Autio, S., Hilvo, M., Sormunen, R., Pastorekova, S., Pastorek, J., Haapasalo, H., Parkkila, S., 2012. Brain phenotype of carbonic anhydrase IX-deficient mice. Transgenic Res. 21, 163-176.

Provensi, G., Costa, A., Passani, M.B., Blandina, P., 2016. Donepezil, an acetylcholine esterase inhibitor, and ABT-239, a histamine H3 receptor antagonist/inverse agonist, require the integrity of brain histamine system to exert biochemical and procognitive effects in the mouse. Neuropharmacology 109, 139-147.

Staley, K.J., Soldo, B.L., Proctor, W.R., 1995. Ionic mechanisms of neuronal excitation by inhibitory GABAA receptors. Science 269, 977-981.

Sun, M.K., Alkon, D.L., 2001. Pharmacological enhancement of synaptic efficacy, spatial learning, and memory through carbonic anhydrase activation in rats. J. Pharmacol. Exp. Ther. 297, 961-967.

Sun, M.K., Alkon, D.L., 2002. Carbonic anhydrase gating of attention: memory therapy and enhancement. Trends Pharmacol. Sci. 23, 83-89.

Supuran, C.T., 2008. Carbonic anhydrases: novel therapeutic applications for inhibitors and activators. Nat. Rev. Drug Discov. 7, 168-181.

Supuran, C.T., 2016. How many carbonic anhydrase inhibition mechanisms exist? J. Enzyme Inhib. Med. Chem. 31, 345-360.

Supuran, C.T., Scozzafava, A., 2007. Carbonic anhydrases as targets for medicinal chemistry. Bioorg Med. Chem. 15, 4336-4350.

Sweatt, J.D., 2001. The neuronal MAP kinase cascade: a biochemical signal integration system subserving synaptic plasticity and memory. J. Neurochem. 76, $1-10$.

Temperini, C., Scozzafava, A., Vullo, D., Supuran, C.T., 2006. Carbonic anhydrase activators. Activation of isoforms I, II, IV, VA, VII, and XIV with L- and Dphenylalanine and crystallographic analysis of their adducts with isozyme II: stereospecific recognition within the active site of an enzyme and its consequences for the drug design. J. Med. Chem. 49, 3019-3027.

Thomas, G.M., Huganir, R.L., 2004. MAPK cascade signalling and synaptic plasticity. Nat. Rev. Neurosci. 5, 173-183.

Thompson, P.J., Baxendale, S.A., Duncan, J.S., Sander, J.W., 2000. Effects of topiramate on cognitive function. J. Neurol. Neurosurg. Psychiatry 69, 636-641.

Waltereit, R., Dammermann, B., Wulff, P., Scafidi, J., Staubli, U., Kauselmann, G., Bundman, M., Kuhl, D., 2001. Arg3.1/Arc mRNA induction by Ca2+ and cAMP requires protein kinase $\mathrm{A}$ and mitogen-activated protein kinase/extracellular regulated kinase activation. J. Neurosci. 21, 5484-5493.

Wang, C., Li, Z., Han, H., Luo, G., Zhou, B., Wang, S., Wang, J., 2016. Impairment of object recognition memory by maternal bisphenol A exposure is associated with inhibition of Akt and ERK/CREB/BDNF pathway in the male offspring hippocampus. Toxicology 341-343, 56-64.

Wang, J., Ke, T., Zhang, X., Chen, Y., Liu, M., Chen, J., Luo, W., 2013. Effects of acetazolamide on cognitive performance during high-altitude exposure. Neurotoxicol. Teratol. 35, 28-33.

Winters, B.D., Saksida, L.M., Bussey, T.J., 2008. Object recognition memory: neurobiological mechanisms of encoding, consolidation and retrieval. Neurosci. Biobehav. Rev. 32, 1055-1070.

Yang, M.T., Chien, W.L., Lu, D.H., Liou, H.C., Fu, W.M., 2013. Acetazolamide impairs fear memory consolidation in rodents. Neuropharmacology 67, 412-418. 